\title{
Successful mucosal incision-assisted biopsy for the histological diagnosis of duodenal lymphoma: A case report
}

\author{
ASAHIRO MORISHITA ${ }^{1}$, HIROHITO MORI ${ }^{1}$, HIDEKI KOBARA ${ }^{1}$, NORIKO NISHIYAMA ${ }^{1}$, SHINTARO FUJIHARA ${ }^{1}$, \\ TATSUO YACHIDA ${ }^{1}$, MAKI AYAKI ${ }^{1}$, TAE MATSUNAGA ${ }^{1}$, TEPPEI SAKAMOTO ${ }^{1}$, EMIKO MAEDA ${ }^{1}$, \\ TAKAKO NOMURA ${ }^{1}$, JOJI TANI ${ }^{1}$, HISAAKI MIYOSHI ${ }^{1}$, HIROHITO YONEYAMA ${ }^{1}$, \\ TAKASHI HIMOTO ${ }^{1}$, SEIKO KAGAWA ${ }^{2}$, REIJI HABA ${ }^{2}$ and TSUTOMU MASAKI ${ }^{1}$
}

Departments of ${ }^{1}$ Gastroenterology and Neurology, and ${ }^{2}$ Diagnostic Pathology, Faculty of Medicine, Kagawa University, Kita, Kagawa 761-0793, Japan

Received November 14, 2014; Accepted September 24, 2015

DOI: $10.3892 / \mathrm{ol} .2015 .3973$

\begin{abstract}
Tissue sampling of primary duodenal lymphoma is essential for its histological diagnosis. Endoscopic ultrasound-guided fine-needle aspiration (EUS-FNA), which is frequently used for submucosal tumor (SMT)-like duodenal tumors, is adequate for cytological diagnosis, but not for histological diagnosis. Therefore, in the present study, a mucosal incision-assisted biopsy (MIAB) was performed in an 81-year-old woman for the diagnosis of an SMT-like duodenal mass, as tissue sampling for histological analysis using a regular endoscopic biopsy had failed to establish a definite diagnosis of malignant lymphoma. EUS-FNA had also led to poor tissue sampling due to the difficult location of the duodenal tumor. The pathological examination of biopsy samples using MIAB revealed the presence of a diffuse proliferation of atypical lymphocytes, and the expression of cluster of differentiation (CD)20 and CD79a, but no expression of CD3 in the tumor specimens. The patient was diagnosed with diffuse large B-cell lymphoma. To the best of knowledge, this is first report of a case using MIAB as a sampling method for the histological diagnosis of SMT-like primary duodenal lymphoma. This case suggests that MIAB may be an essential method for obtaining tissue samples from SMT-like duodenal tumors.
\end{abstract}

\section{Introduction}

The gastrointestinal (GI) tract is one of the most common extranodal sites of non-Hodgkin's lymphoma (NHL),

Correspondence to: Professor Tsutomu Masaki, Department of Gastroenterology and Neurology, Faculty of Medicine, Kagawa University, 1750-1 Ikenobe, Miki-cho, Kita-gun, Kagawa 761-0793, Japan

E-mail: tmasaki@med.kagawa-u.ac.jp

Key words: mucosal incision-assisted biopsy, duodenal lymphoma, submucosal tumor, endoscopic ultrasound-guided fine-needle aspiration, histological diagnosis accounting for $20-40 \%$ of all NHL cases (1). Approximately $50 \%$ of all primary GI lymphomas are identified in the stomach, and 14-38\% of cases are found in the small intestine, including duodenal lymphoma (2). Duodenal lymphomas account for $0.8-2 \%$ of all GI lymphomas $(3,4)$ and symptoms include anorexia, abdominal pain and weight loss (5). The median survival time of primary GI lymphoma patients following diagnosis is reported to be 54 months (3). Among GI lymphomas, accurate diagnosis of submucosal tumor (SMT)-like tumors is complicated as it is difficult to obtain a sufficient sample of submucosal tissue for diagnostic examination. Submucosal tumor (SMT)-like duodenal tumors are sometimes found to be malignant lymphomas. Although endoscopic ultrasonography (EUS), a procedure that uses ultrasound to endoscopically examine the wall of the GI tract, is one of the most useful modalities for the diagnosis of SMT, it is not always effective in distinguishing between malignant lymphomas and other types of tumors. As histological analyses are essential for the diagnosis of lymphoma, endoscopic ultrasound-guided fine-needle aspiration (EUS-FNA) has recently been used as an endoscopic tissue sampling method for these duodenal tumors (6). However, this technique remains inadequate for immunohistological analyses due to limitations imposed by a large sample size $(7,8)$. Recently, mucosal incision-assisted biopsy (MIAB), a novel technique used to obtain tissue samples from SMT-like tumors using the endoscopic submucosal dissection (ESD) method, has been reported for the histological diagnosis of gastric GI stromal tumors (GISTs) (9). The present study demonstrates, to the best of our knowledge, the first case with the application of MIAB as a sampling method for the histological diagnosis of SMTlike duodenal malignant lymphoma.

\section{Case report}

In August 2013, an 81-year-old woman presented to Kagawa University Hospital (Kagawa, Japan) with abdominal distension. An enhanced computed tomography scan revealed a duodenal tumor associated with increased wall thickness (Fig. 1). A positron emission tomography scan also indicated an abnormal uptake of tracer in the duodenum (Fig. 2). 


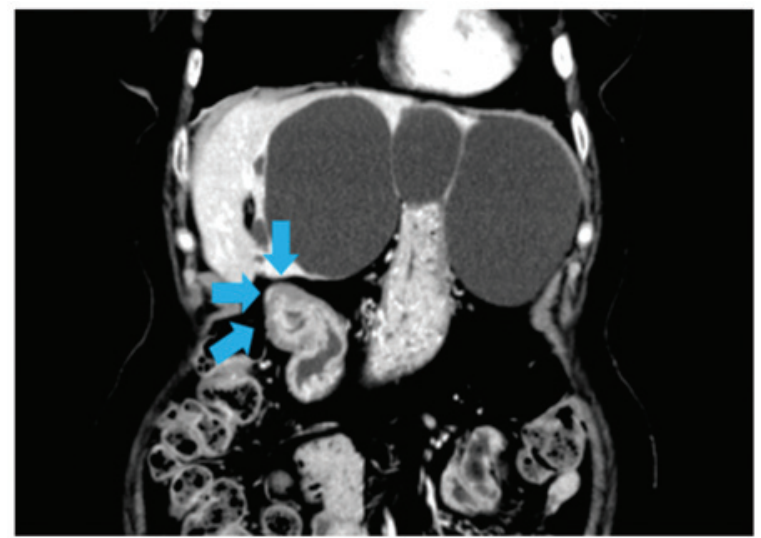

Figure 1. Enhanced computed tomography scan of an 81-year-old woman showing increased duodenal wall thickness (blue arrows).
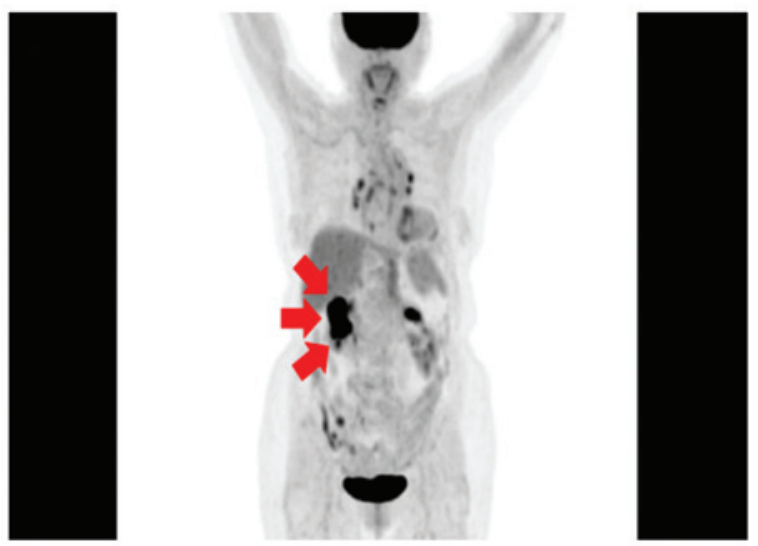

Figure 2. Positron emission tomography scan of the duodenum showing the abnormal uptake of tracer (red arrows).

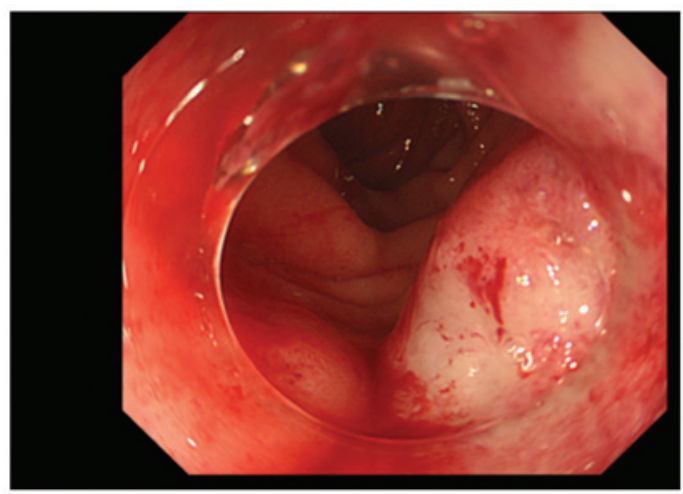

Figure 3. Endoscopic evaluation revealing a submucosal tumor, $25 \mathrm{~mm}$ in diameter, located in the superior duodenal angle.

The endoscopic examination showed the presence of an SMT, $\sim 25 \mathrm{~mm}$ in diameter, located in the superior duodenal angle (Fig. 3). EUS revealed that the lesion originated from the fourth layer (muscularis propria) of the duodenum (Fig. 4). EUS-FNA was attempted for tissue sampling, but failed due to the difficult location of the tumor. Therefore, after obtaining the patient's informed consent, a MIAB was performed. A $10-\mathrm{cm}$ mucosal incision exposed the surface

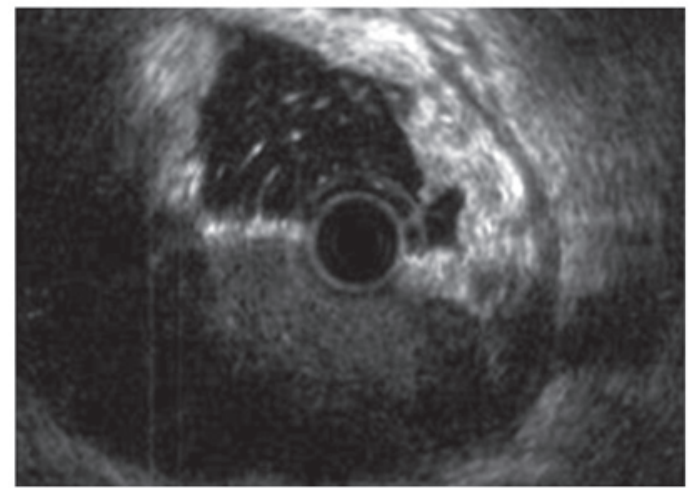

Figure 4. Endoscopic ultrasound showing the submucosal tumor-like mass located in the fourth layer (muscularis propria) of the duodenum.

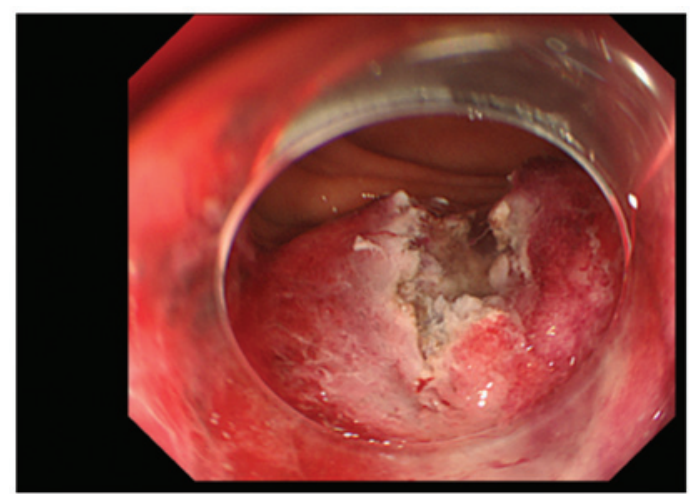

Figure 5. Endoscopic view showing the 10-mm mucosal incision, exposing the white-colored tumor at the apex of the submucosal tumor.

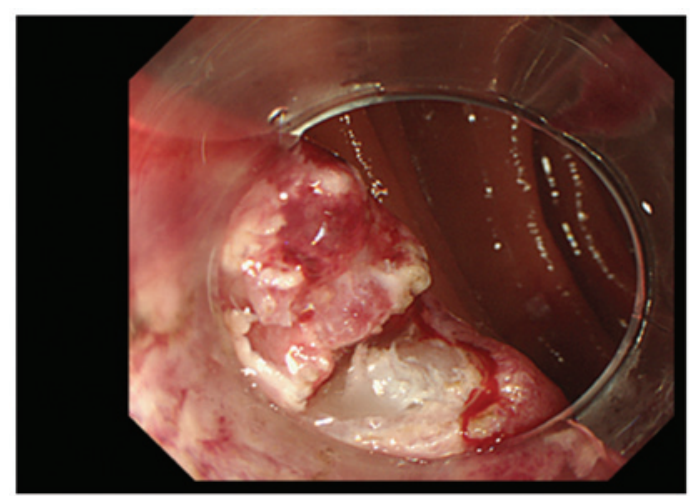

Figure 6. Endoscopic image following a successful mucosal incision-assisted biopsy.

of the SMT apex (Fig. 5), and tissue samples were successfully obtained, followed by closure of the mucosal incision using hemoclips (Fig. 6). No complications were detected after MIAB. The pathological examination of the biopsy samples revealed the presence of a diffuse proliferation of atypical lymphocytes, and the expression of cluster of differentiation (CD)20 and CD79a, but no expression of CD3 in the tumor specimens (Fig. 7). The patient was diagnosed with diffuse large B-cell lymphoma and immediately received eight cycles of treatment with a 3 -week chemotherapy regimen (375 $\mathrm{mg} / \mathrm{m}^{2}$ rituximab, day $1 ; 30 \mathrm{mg} / \mathrm{m}^{2}$ tetrahydropyranyl 

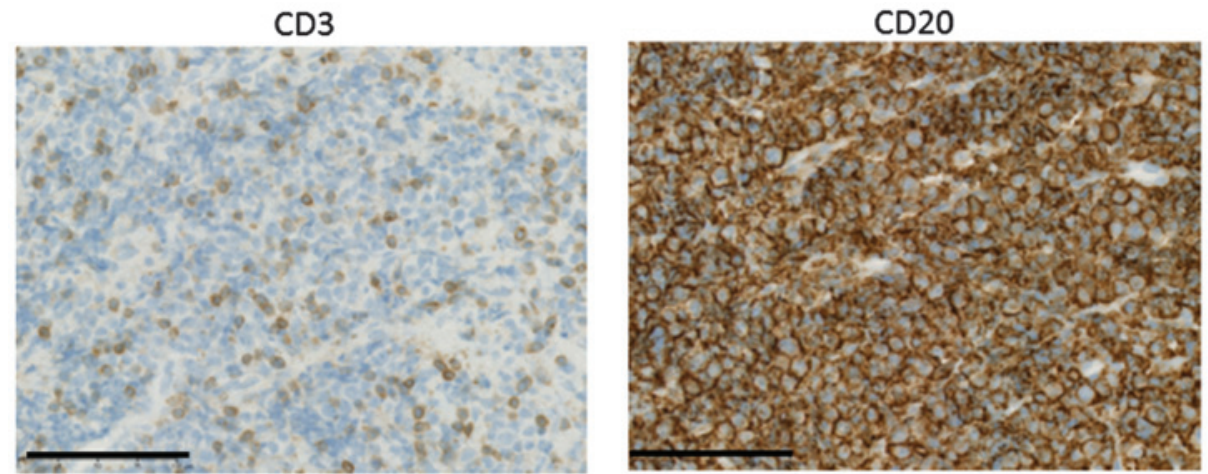

H.E.

CD79a
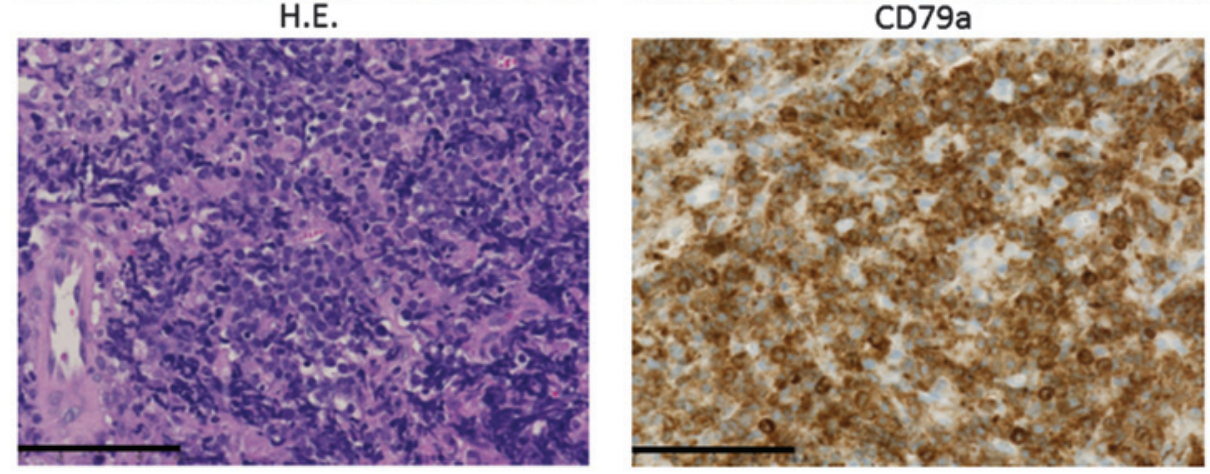

Figure 7. Immunohistochemistry of duodenal submucosal tumor-like mass obtained by mucosal incision-assisted biopsy. Scale bar, $100 \mu \mathrm{m}$. CD, cluster of differentiation; H.E., hematoxylin and eosin.

adriamycin, day $2 ; 500 \mathrm{mg} / \mathrm{m}^{2}$ cyclophosphamide, day 2 ; $1.0 \mathrm{mg} / \mathrm{m}^{2}$ vincristine, day 2 ; and $30 \mathrm{mg} / \mathrm{m}^{2}$ prednisolone, days 2-7). The patient was followed up 27 months following $\mathrm{MIAB}$, and exhibited a complete response.

\section{Discussion}

Tissue sampling is essential for the histological diagnosis of SMTs, as they comprise both benign and malignant lesions $(8,10)$. EUS-FNA has been established as a preferred method for tissue sampling due to its accuracy and safety, but it occasionally fails to provide adequate samples for histological diagnosis (8). In a previous study, the diagnostic yield from EUS-FNA was reported to provide adequate samples in 117/141 (83.0\%) patients with gastric SMTs. In 29/117 cases, tissue samples were adequate for a possible diagnosis by cytological examination, but inadequate for histological diagnosis (8). Hence, adequate samples were only obtained in $88 / 141(62.4 \%)$ cases. In the present study, adequate samples were required to diagnose a malignant lymphoma. Additionally, due to the location of the SMT-like mass in the supraduodenal angle, it was technically difficult to perform EUS-FNA. Therefore, a MIAB was performed to diagnose this duodenal tumor.

Previous studies have demonstrated the endoscopic histological diagnosis of GISTs using ESD techniques, including MIAB $(9,11)$. Lee et al (11) revealed that endoscopic biopsies using ESD techniques were sufficient for staining of all biopsy specimens obtained from SMT-like tumors, including leiomyoma, lipoma and ectopic pancreas. One of the most advantageous aspects of performing MIAB is the ability to harvest sufficient quantities of tissue samples for the definitive diagnosis of lymphoma $(9,11)$. However, potential disadvantages are procedure-related complications, including bleeding and perforation. In particular, procedure-related bleeding by MIAB is a frequent complication that is easily controlled by hemostatic procedures (12). With regard to potential late complications, such as post-operative bleeding and perforation, mucosal closure with hemoclips after tissue sampling has been used successfully (13).

In conclusion, the present study demonstrated, for the first time, a case using MIAB as a sampling method for the histological diagnosis of SMT-like primary duodenal malignant lymphoma. This case suggests that MIAB may be a novel, valuable, tissue sampling method for the diagnosis of SMTlike duodenal tumors.

\section{References}

1. Yoo CC, Levine MS, McLarney JK, Rubesin SE and Herlinger H: Value of barium studies for predicting primary versus secondary non-Hodgkin's gastrointestinal lymphoma. Abdom Imaging 25: 368-372, 2000

2. Yaranal PJ, Harish SG and Purushotham B: Primary intestinal lymphoma: A clinicopathological study. Indian J Cancer 51: 306-308, 2014.

3. Cirillo M, Federico M, Curci G, Tamborrino E, Piccinini L and Silingardi V: Primary gastrointestinal lymphoma: A clinicopathological study of 58 cases. Haematologica 77: 156-161, 1992.

4. Domizio P, Owen RA, Shepherd NA, Talbot IC and Norton AJ: Primary lymphoma of the small intestine. A clinicopathological study of 119 cases. Am J Surg Pathol 17: 429-442, 1993.

5. Boddie AW Jr, Eisenberg BL, Mullins JD and Schlichtemeier AL: The diagnosis and treatment of obstructive jaundice secondary to malignant lymphoma: A problem in multidisciplinary management. J Surg Oncol 14: 111-123, 1980.

6. Larghi A, Fuccio L, Chiarello G, Attili F, Vanella G, Paliani GB, Napoleone M, Rindi G, Larocca LM, Costamagna G and Ricci R: Fine-needle tissue acquisition from subepithelial lesions using a forward-viewing linear echoendoscope. Endoscopy 46: 39-45, 2014. 
7. Hoda KM, Rodriguez SA and Faigel DO: EUS-guided sampling of suspected GI stromal tumors. Gastrointest Endosc 69: 1218-1223, 2009.

8. Mekky MA, Yamao K, Sawaki A, Mizuno N, Hara K, Nafeh MA, Osman AM, Koshikawa T, Yatabe Y and Bhatia V: Diagnostic utility of EUS-guided FNA in patients with gastric submucosal tumors. Gastrointest Endosc 71: 913-919, 2010.

9. Ihara E, Matsuzaka H, Honda K, Hata Y, Sumida Y, Akiho H, Misawa T, Toyoshima S, Chijiiwa $Y$, Nakamura $\mathrm{K}$ and Takayanagi R: Mucosal-incision assisted biopsy for suspected gastric gastrointestinal stromal tumors. World J Gastrointest Endose 5: 191-196, 2013.

10. Turhan N, Aydog G, Ozin Y, Cicek B, Kurt M and Oguz D: Endoscopic ultrasonography-guided fine-needle aspiration for diagnosing upper gastrointestinal submucosal lesions: A prospective study of 50 cases. Diagn Cytopathol 39: 808-817, 2011.
11. Lee HL, Kwon OW, Lee KN, Jun DW, Eun CS, Lee OY, Jeon YC, Han DS, Yoon BC, Choi HS, et al: Endoscopic histologic diagnosis of gastric GI submucosal tumors via the endoscopic submucosal dissection technique. Gastrointest Endosc 74: 693-695, 2011.

12. Kobara H, Mori H, Fujihara S, Nishiyama N, Kobayashi M, Kamata $\mathrm{H}$ and Masaki T: Bloc biopsy by using submucosal endoscopy with a mucosal flap method for gastric subepithelial tumor tissue sampling (with video). Gastrointest Endosc 77: 141-145, 2013.

13. Kataoka M, Kawai T, Yagi K, Sugimoto H, Yamamoto K, Hayama Y, Nonaka M, Aoki T, Fukuzawa M, Fukuzawa M, et al: Mucosal cutting biopsy technique for histological diagnosis of suspected gastrointestinal stromal tumors of the stomach. Dig Endosc 25: 274-280, 2013. 